\title{
Modeling and Simulation of Process-Machine Interaction in Grinding of Cemented Carbide Indexable Inserts
}

\author{
Wei Feng, ${ }^{1}$ Bin Yao, ${ }^{1}$ BinQiang Chen, ${ }^{2}$ DongSheng Zhang, ${ }^{3}$ \\ XiangLei Zhang, ${ }^{1}$ and ZhiHuang Shen ${ }^{1}$ \\ ${ }^{1}$ Department of Mechanical and Electrical Engineering, School of Physics and Mechanical \& Electrical Engineering, \\ Xiamen University, Xiamen 361005, China \\ ${ }^{2}$ State Key Laboratory for Manufacturing and Systems Engineering, School of Mechanical Engineering, Xian Jiaotong University, \\ Xian 710049, China \\ ${ }^{3}$ School of Mechanical Engineering, Shaanxi University of Technology, Hanzhong 723001, China
}

Correspondence should be addressed to Bin Yao; yaobin@xmu.edu.cn

Received 26 August 2014; Accepted 15 October 2014

Academic Editor: Yaguo Lei

Copyright (C) 2015 Wei Feng et al. This is an open access article distributed under the Creative Commons Attribution License, which permits unrestricted use, distribution, and reproduction in any medium, provided the original work is properly cited.

Interaction of process and machine in grinding of hard and brittle materials such as cemented carbide may cause dynamic instability of the machining process resulting in machining errors and a decrease in productivity. Commonly, the process and machine tools were dealt with separately, which does not take into consideration the mutual interaction between the two subsystems and thus cannot represent the real cutting operations. This paper proposes a method of modeling and simulation to understand well the process-machine interaction in grinding process of cemented carbide indexable inserts. First, a virtual grinding wheel model is built by considering the random nature of abrasive grains and a kinematic-geometrical simulation is adopted to describe the grinding process. Then, a wheel-spindle model is simulated by means of the finite element method to represent the machine structure. The characteristic equation of the closed-loop dynamic grinding system is derived to provide a mathematic description of the processmachine interaction. Furthermore, a coupling simulation of grinding wheel-spindle deformations and grinding process force by combining both the process and machine model is developed to investigate the interaction between process and machine. This paper provides an integrated grinding model combining the machine and process models, which can be used to predict process-machine interactions in grinding process.

\section{Introduction}

High performance cutting tools play an important role in modern manufacturing. To some extent, the performance of a cutting tool determines the cutting behavior and the process capability. With recent developments in aerospace and automobile industries, there are increasing demands for high-quality parts $[1,2]$. In order to meet the urgent requirements for high quality parts, cutting tools made of cemented carbide are used, which is a very hard and brittle material.

Due to the hardness of cemented carbide cutting tools are mainly manufactured by grinding process. Grinding is one of the most common material removal processes to achieve desired surface integrity, dimensional tolerance, and form tolerance. It is used as a typical finishing process as well as for high material removal rates. In the grinding process, the machine tools and process constitute a closed loop machining system. The generated cutting forces and temperature cause elastic deformations in the machine tool system which change the instantaneous chip area which in turn has an influence on the cutting forces.

During precision machining, the dynamic interactions between machining process and grinding machine structure, for example, vibrations, deflections, or thermal deformations, result in poor quality of produced parts, short life of machine components and tools [3,4]. Different methods have been developed and used to detect and diagnose the 
machine faults [5-7]. In the past, the process and machine tools were dealt with separately. However, the separation of the machining system into the two subsystems does not take into consideration the mutual interaction between the two subsystems and thus cannot represent the real cutting operations. The continuous and mutual influence exerted by both machine and process results in the often unpredictable effects in precision grinding of hard and brittle materials such as cemented carbide, which may cause dynamic instability of the machining process resulting in machining errors and a decrease in productivity.

In order to meet requirements of high accuracy and productivity in grinding of cemented carbide cutting tools, it is essential to understand well the interaction between the process and the machine tool system linked with the force and the deformation. The interaction between process and machine is usually hard to predict due to its complexity, and extensive experiments are laborious and expensive. In many cases, predictions can only be made by means of complex simulations [3]. There has been numerous researches conducted to the modeling and simulation of grinding processes in the last two decades; however, commonly most focus on simulation of local contact area interaction between the grinding wheel and workpiece and neglect displacements of the machine system [8-12]. Once vibrations and deformations of machine structure caused by process forces can be determined, strategies can be derived to reduce geometry as well as thermomechanical errors by process parameter and tool path optimization [4]. Therefore, it is necessary to treat process and machine structure in an integrated way.

The prediction of process-machine interactions requires models of machine and process. To predict the interactions these models have to be built and then coupled and simulated. Due to the large number of abrasive grains with unknown time-dependent geometry and distribution, grinding is a complex material-removal process [13]. Based on kinematicgeometrical simulations, numerous macroscopic and microscopic approaches have been used to build the grinding process model up to now [9]. On the machine tool side, the integrated models providing data on static and dynamic behavior of the structure must be appropriately parameterized. Multiple approaches for building a machine model are presented in [10].

The simulation of cutting processes under consideration of process and machine properties can be carried out along with different methods. The coupled simulation was a relatively new approach which permits simultaneous usage of two different simulation environments with data exchange by means of a suitable interface [3]. Brecher and Witt [14] proposed an approach for simulating a machining process, including interactions between machine tool and a cutting process. Three different approaches were used to carry out a coupled simulation of machine and process. Herzenstiel et al. [15] developed a comprehensive simulation of the grinding process and the grinding machine. They combined the process model (KSIM) and the machine model (FEM) and proposed a staggered iteration scheme. Weinert et al. [16] used a cosimulation comprising a geometric-kinematical process simulation and a finite elements simulation to

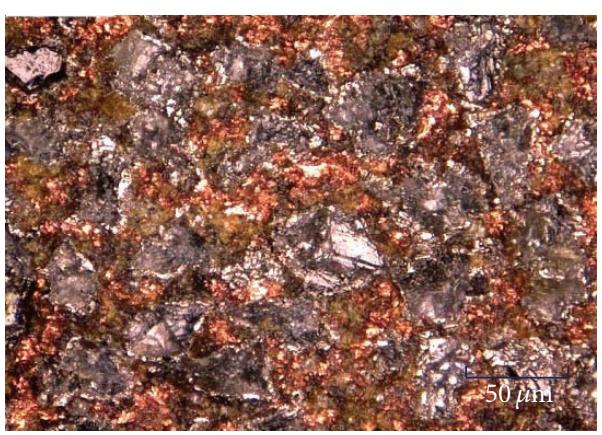

FIGURE 1: Topographies of grinding wheel.

investigate NC shape grinding. The authors also provided an iterative solution for nonlinear process-structure coupling problems. Aurich and Kirsch [17] presented new insights in the modeling process and the examination of processmachine interactions using kinematic simulation.

In this paper, the interaction of process and machine in cemented carbide insert grinding is studied. The authors propose a geometric-kinematical simulation and a wheelspindle model based on finite element method. Furthermore, a couple simulation approach which treats the grinding process and machine tool structure in an integrated manner is presented. Also, an investigation of the results of processmachine interaction is described.

\section{Process Model}

A kinematic-geometrical simulation model (KSIM) is adopted in this research work, which was first developed by Warnecke and Zitt [18]. The concept of KSIM is based on the observed micro- and macroscopic cause and effect chain in grinding and simulates the grinding process as a penetration between the enveloping profile of the grinding wheel and the workpiece [17]. Therefore, the micro and macro geometry of the grinding wheel and workpiece have to be modeled. In the simulation, ideal cutting is assumed by not taking account of rubbing and ploughing of materials and each grain removes the whole material volume encountered. In the simulation, the loads and stresses can be calculated in FEM for every single grain by using material models. On the other hand, the forces that are generated can be calculated using modified Kienzle equations together with the knowledge of the accumulated machined material and the chip corss-section [3].

2.1. Modeling of the Grinding Wheel. To gain realistic simulation results the grinding wheel topography has to be modeled precisely. The topography of a diamond wheel in a stationary wear state was measured by using a KEYENCE VHX-5000 3D-measuring system. Figure 1 shows the top view of the topography at working face. As can be seen from Figure 1, the real geometry of single grain is similar to pyramid; therefore hexahedron was chosen in this work for mathematical simplification in modeling. It is noted that the process model to be built requires considering the combined 


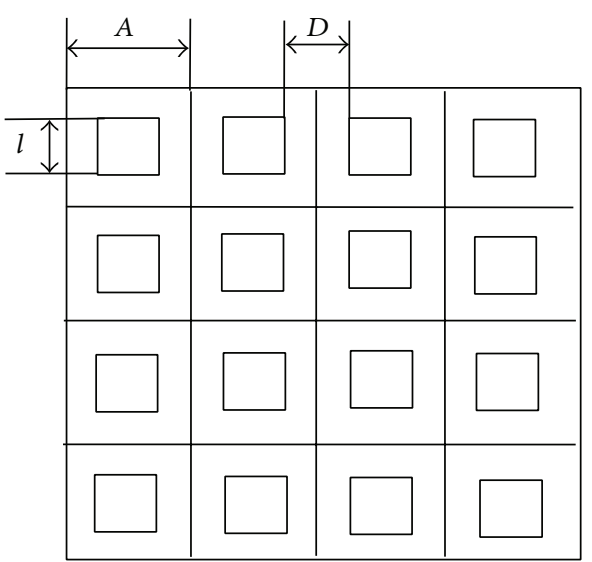

FIGURE 2: Virtual grids of abrasive grains distribution.

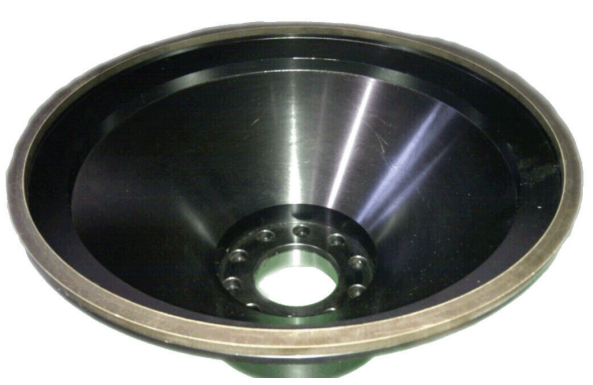

FIGURE 3: Virtual grinding wheel archetype.

action of the grains which are stochastically spaced in the grinding wheel. The authors proposed a novel approach to take account for the random nature of grinding wheel [19]. The average grit spacing is estimated by using the density of the grits. The location of each grain is represented by its center coordinate. The spatial probability distribution of the grains is obtained by adjusting the location of each individual grain center in three-dimensional space.

In order to avoid the overlapping between abrasive grains in the binder, a virtual grid approach is used to account for the random nature of the grinding wheel. Assuming abrasive grains are distributed in a square area of the grinding wheel and each grain is restrained in an imaginary grid, see Figure 2. $A$ is the length of the virtual grid which depends on the grain density. $D$ is the diameter of the grain. The location coordinates of the grains are randomly distributed in a $l \times l$ square area.

The major components of the topography of grinding wheel are abrasive grains and bonds. Since only the grains participate in actual cutting process, the influence of binds is neglected in modeling. For modeling the grinding, a real diamond $12 \mathrm{~A} 2 \mathrm{~T}$ grinding wheel in stationary wear state with a dimension of $\Phi 400 \times 4.8 \mathrm{~mm}$ was used as archetype; see Figure 3. The density of the grits was 127 per $\mathrm{mm}^{2}$ and the nominal grit size was between $50 \mu \mathrm{m}$ and $70 \mu \mathrm{m}$. As to the grain geometry, a hexahedron with each side length of $50 \mu \mathrm{m}$ was adopted. A method in [19] was used to build the detail

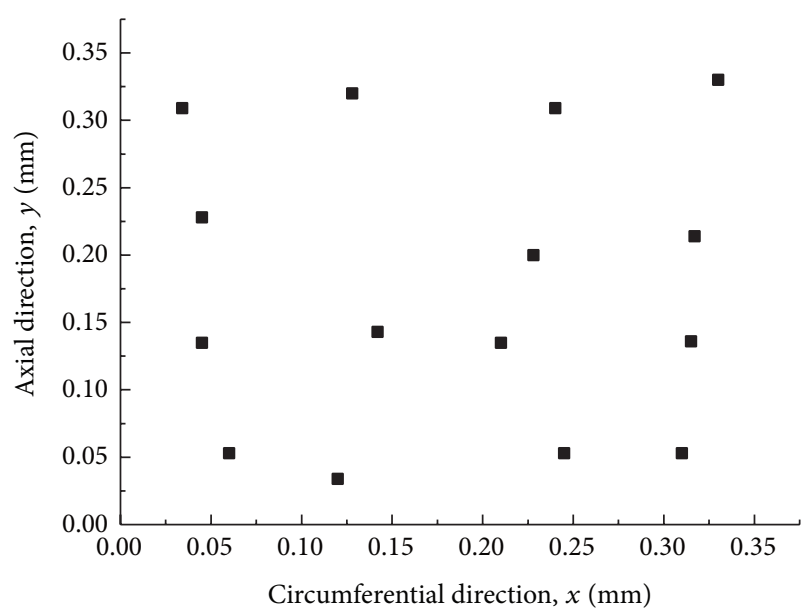

FIGURE 4: Random position coordinates of grains.

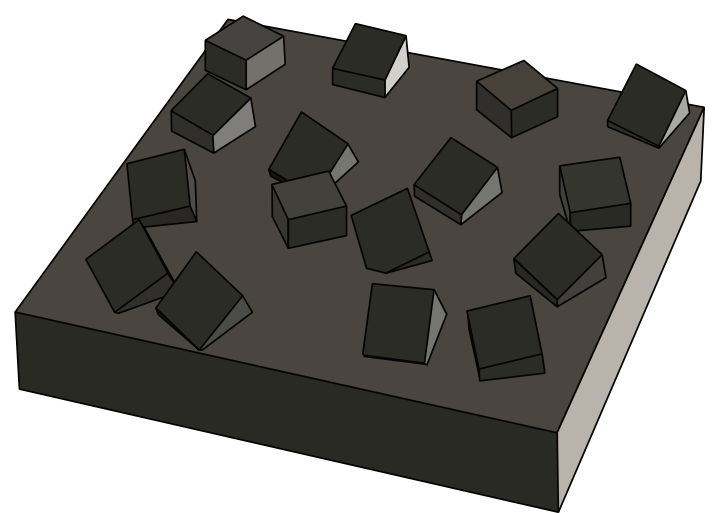

FIGURE 5: Modeled grinding wheel section.

grinding wheel model. First, the random position coordinates of the abrasive grains were generated; see Figure 4. Then, the geometry model was built with a commercial threedimensional software. For a section of the modeled virtual grinding wheel, see Figure 5.

2.2. Process Model. With the grinding wheel model at hand, simulations for different combinations of the input grinding parameters can be conducted. In the simulation, ideal cutting is assumed neglecting ploughing and friction effects; therefore the process force at a given time depends linearly on the cutting depth based on Kienzle approach:

$$
F(t)=k_{c} \cdot \Delta(t),
$$

where $k_{c}$ denotes the process stiffness. The output parameters of the simulation are the experimentally not measurable undeformed chip thickness, chip length, chip width and chip cross section of every single grain. Using the simulated chip cross section from simulation, the process force can be calculated. Process stiffness $k_{c}$ is an experimentally determined parameter, which can be determined by executing series of tests. In this work, the face grinding of a cemented carbide indexable insert is investigated; see Figure 6. The details of the 


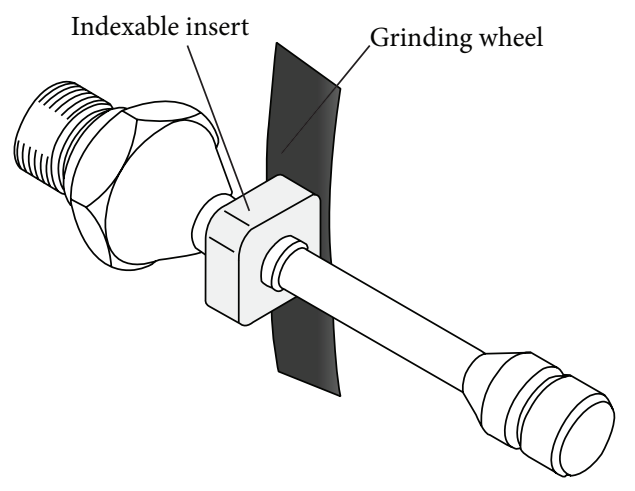

FIGURE 6: Cemented carbide cutting insert grinding.

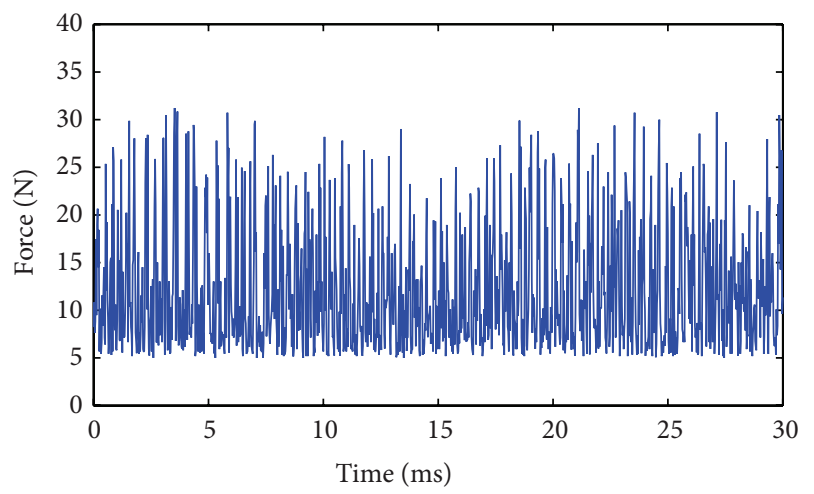

Grinding wheel speed: $42 \mathrm{~m} / \mathrm{s}$ Grinding depth: $0.02 \mathrm{~mm}$ Feed speed: $300 \mathrm{~mm} / \mathrm{min}$

FIGURE 7: Simulated process force.

grinding tests can be found in [19]. It has to be noted that the grinding tests conducted in this work were based on a fixed $y$-axis, which was different from [19].

The exemplary parameter combination of cutting speed $42 \mathrm{~m} / \mathrm{s}$, depth of cut $0.02 \mathrm{~mm}$, and feed rate $300 \mathrm{~mm} / \mathrm{min}$ was chosen to show and explain the results of simulation. In Figure 7 the grinding force for one wheel revolution of the simulated process force is depicted. Due to the constant change of protrusion heights on the topography of grinding wheel, the chip cross-sectional areas fluctuate and result in an oscillating simulated force signal.

\section{Machine Model}

For an exact simulation of the mutual interaction between grinding process and machine, the machine structure has to be modeled accurately. Therefore the machine model has to be able to respond to excitations coming from the grinding process and to create an output which again has an influence on the calculated grinding process. Since the modeling of a complete machine is usually very complex and time consuming, if some of the machine components react to an excitation by the grinding process, a selective model can be adopted [4]. The main modeling methods for grinding

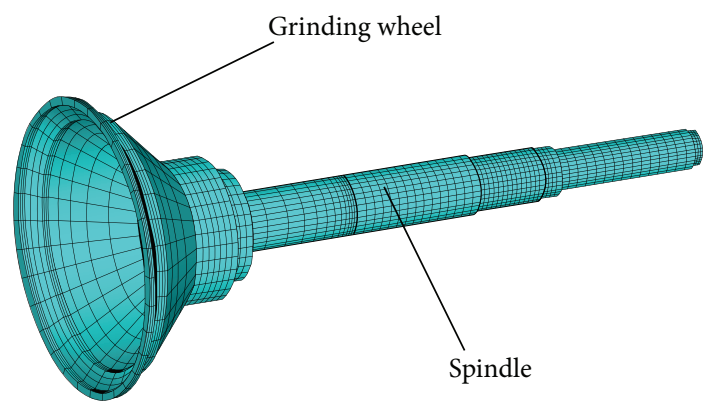

FIgURE 8: Wheel-spindle FE model.

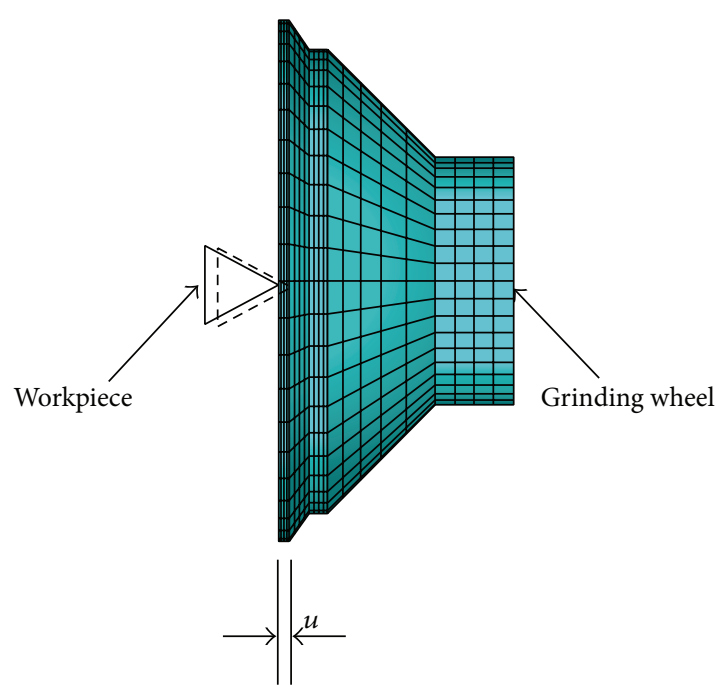

Figure 9: Point contact.

TABLE 1: Material properties of spindle and wheel hub.

\begin{tabular}{lcc}
\hline & Steel & $40 \mathrm{Cr}$ \\
\hline Density $\left[\mathrm{kg} / \mathrm{m}^{3}\right]$ & 7890 & 7870 \\
Young modulus $[\mathrm{GPa}]$ & 209 & 211 \\
Poisson's ratio & 0.269 & 0.277 \\
\hline
\end{tabular}

machines are finite element, multibody simulation, boundary element, and analytical methods [3]. In this work, a wheelspindle finite element (FE) model is chosen and built; see Figure 8 . The spindle is made of steel and the wheel hub is made of 40Cr. Material properties are listed in Table 1. Apart from the wheel-spindle model, the contact between wheel and workpiece can be simplified to single point contact [12]; see Figure 9. Accordingly, only one node is in contact. The contact force returned for a single contact point is a function of time and displacements.

For parameterising the wheel-spindle model, static and dynamic behavior of the real machine must be measured and characterized accurately. A modal experiment was conducted by using an impact hammer instrumented with a piezoelectric transducer and an accelerometer. Then the measured eigenfrequencies were compared with the results of the modal analysis by using commercial FEA software to verify and validate the related FE model. All eigenfrequencies extracted 


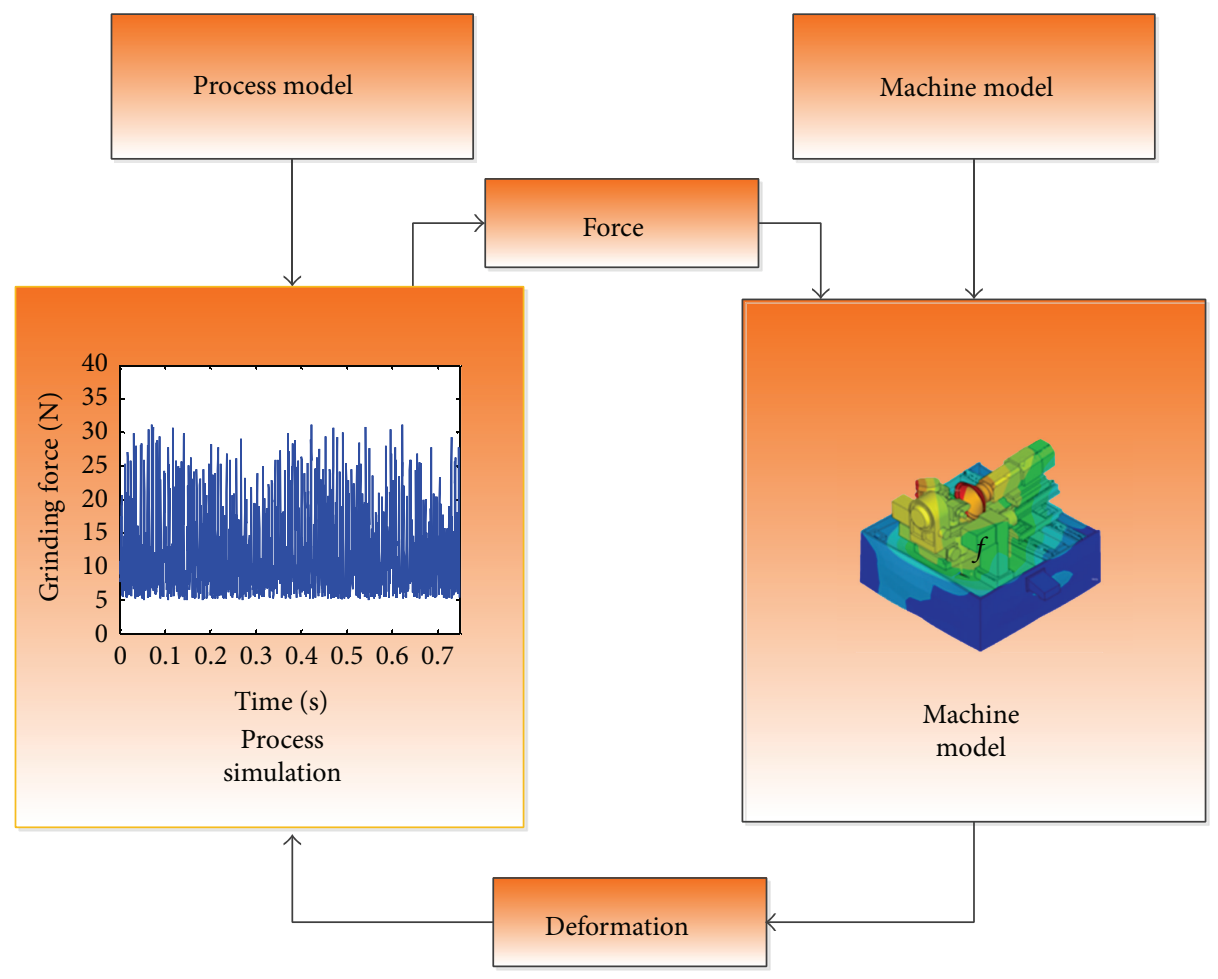

FIgURE 10: Coupling simulation of process-machine interaction.

TABLE 2: Eigenmodes 1-5 extracted from experimental data and FE simulations.

\begin{tabular}{lccc}
\hline Mode & Experiment $[\mathrm{Hz}]$ & FE model $[\mathrm{Hz}]$ & Difference [\%] \\
\hline 1 & 220 & 215.62 & $1.99 \%$ \\
2 & 330 & 353.64 & $7.16 \%$ \\
3 & 780 & 753.23 & $3.43 \%$ \\
4 & 950 & 929.53 & $2.16 \%$ \\
5 & 1050 & 1019 & $2.95 \%$ \\
\hline
\end{tabular}

from FE simulations are well matched to the experimental data; see Table 2.

\section{Process-Machine Interaction}

4.1. Modeling of Process-Machine Interaction. Assuming the dynamic displacements of machining system under excitation of grinding process forces at a given time will be

$$
x(t)=\Delta(t)-\Delta(t-T),
$$

where $\Delta(t)$ and $\Delta(t-T)$ are the present and past instantaneous grinding depth, $T$ is grinding rotation period. Assuming the nature frequency of the machine tool is $w$, the variation of dynamic displacement $x(t)$ in the frequency domain can be represented as

$$
X(i w)=G_{m}(i w) F(i w),
$$

where $G_{m}(i w)$ is the transfer function of the machine tool. Convert (1) and (2) from the time domain to the frequency domain and combine with (3); we can obtain the characteristic equation of the closed-loop dynamic grinding system

$$
\left[1-\left(1-e^{-i w T}\right) k_{c} G_{m}(i w)\right] \Delta(i w)=0 .
$$

With (4) the dynamic behavior of machine tool $G_{m}(i w)$ and the grinding parameters $k_{c}, \Delta$ are linked. The dynamic forces generated in grinding process continually excite the machine structure. The local cutting depth of grinding wheel varies, which in turn influences the grinding force. When the exciting frequency approaches the nature frequency of the machine structure, instability of the grinding process occurs.

4.2. Coupling Simulation. In order to simulate the interaction of grinding process and machine structure, a coupling simulation method is adopted in this work. In coupling simulation, both simulations run simultaneously in different simulation environments and communicated to each another in synchronized cycles [3]; see Figure 10.

A simulation cycle is developed in a coupling simulation. First, a simulated force signal generated by the process model starts as input data for the machine model. The machine model delivers displacements related to the contact zone for one wheel revolution, which again constitutes input data for the process model. Equation (1) is only valid for an ideally stiff grinding wheel; however, grinding wheel has axial deformation $u$ due to forces in grinding process; see Figure 9. Assuming the initial grinding depth is $\Delta_{0}$, the actual grinding depth will be $\left(\Delta_{0}+u\right)$. By multiplying $\left(\Delta_{0}+u\right)$ by the process stiffness $k_{c}$ an adjusted force value is then obtained and can be subsequently used to calculate the deformation again. Since 


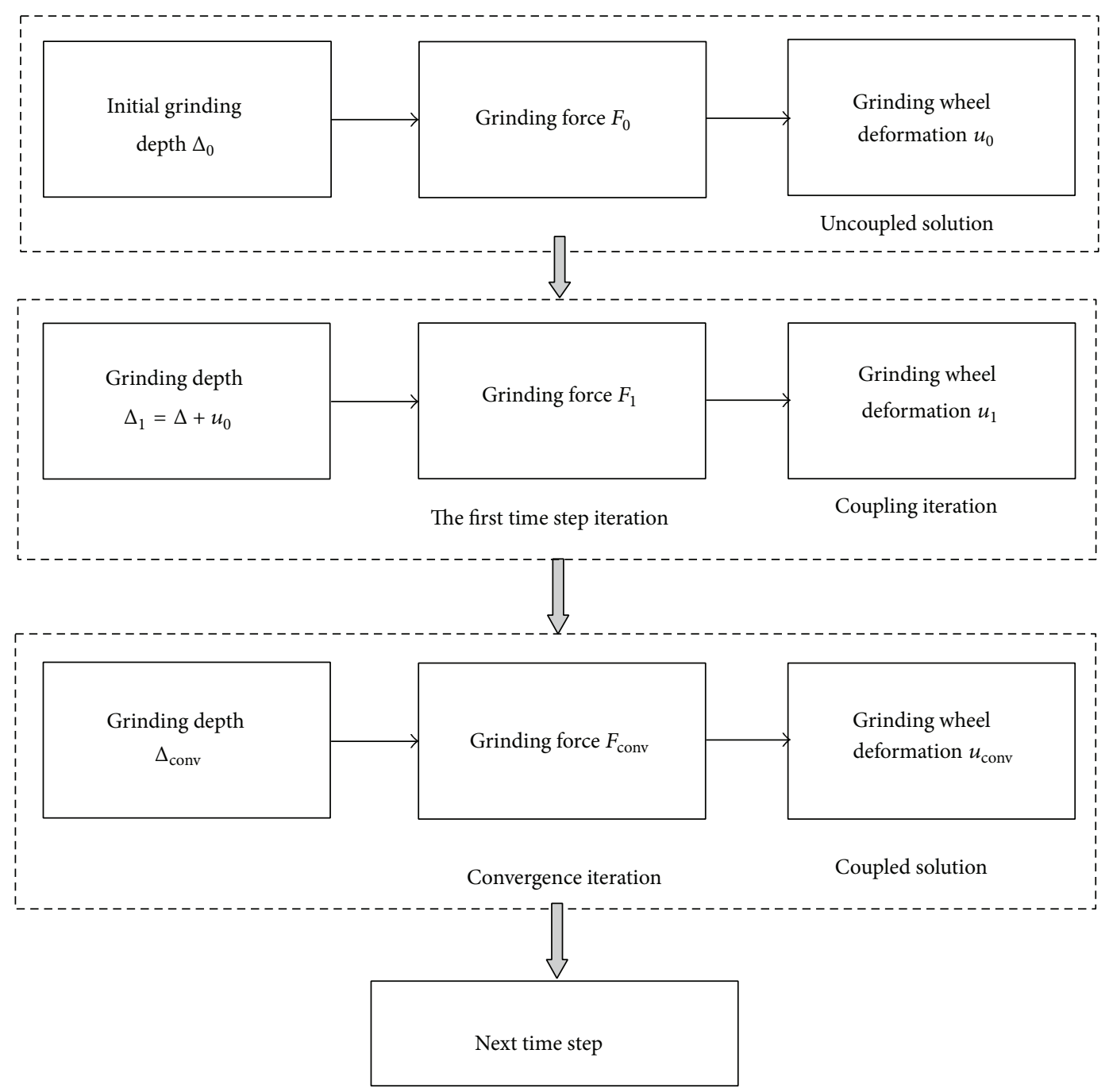

FIgURE 11: Data exchange and convergence for iteration process.

the process and machine state vary in time, the coupling simulation has to be solved iteratively. Weinert et al. proposed an iteration approach to solve the problem [16]. In order to evaluate the process and machine state after each iteration step, the convergence criteria have to be given. The iteration is repeated until the simulated force or displacement signals of two consecutive iteration steps show minor deviations; see Figure 11. Figure 12 shows the mean values for force and the displacement converge over one grinding wheel revolution after 5 iterations from $(31.9 \mathrm{~N}, 11.56 \mu \mathrm{m})$ to $(29.2 \mathrm{~N}, 8.5 \mu \mathrm{m})$. These values are smaller than the values corresponding to the uncoupled solution.

4.3. Coupling Results. A fast Fourier transform of the force signal in Figure 6 shows the exciting frequencies of grinding forces with a dominating contribution of frequencies of up to $1100 \mathrm{~Hz}$; see Figure 13. As can be seen from Figure 13, the dominating frequencies of force signal cover the top 5 order frequencies of wheel-spindle structure. The force signal can be substituted by a set of harmonic function of harmonic depths of cut and the generated harmonic loads are able to excite the grinding wheel. The force and the deformation are normalized so that they can be represented in the same diagram [20]. All forces shown are normalized by dividing the amplitudes of the initial force value. And all deformations are normalized by dividing the maximum deformation value.

Considering the force and deformation in one wheel revolution, the coupling simulation between grinding wheel and process is performed in a set of harmonic grinding depths with a fixed amplitude of $20 \mu \mathrm{m}$ and a fixed frequency of $210 \mathrm{~Hz}$, which corresponds to an eigenfrequency of wheelspindle structure. Figure 14 shows that the effectively applied force and the resulting deformation oscillate with the same frequencies and they are inversely influenced by each other. The frequency corresponding to the eigenfrequency of the machine may lead to a nonstable process. Figure 15 shows that through coupling the effective force signal acquires smaller amplitudes than the initial one. The effective force acting at the grinding wheel is smaller than the value corresponding to the uncoupled solution, and the effective force is only 


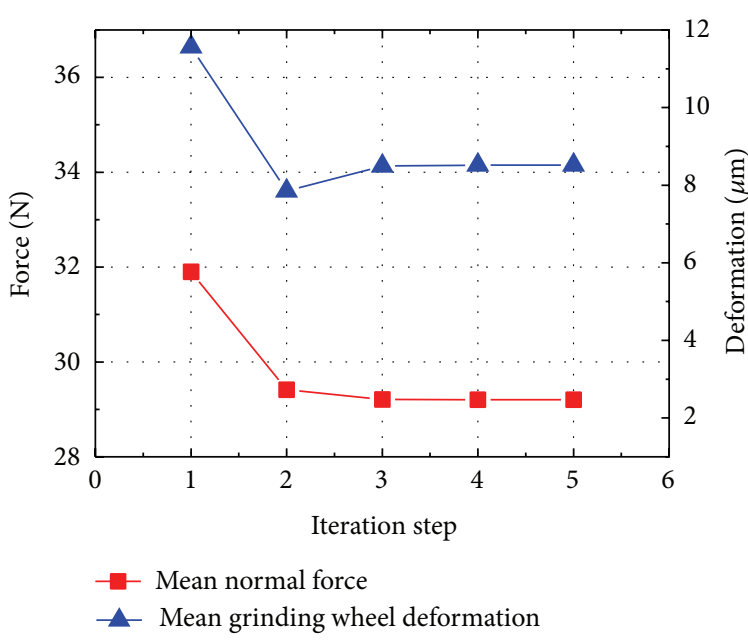

FIGURE 12: Iteration convergence behavior.

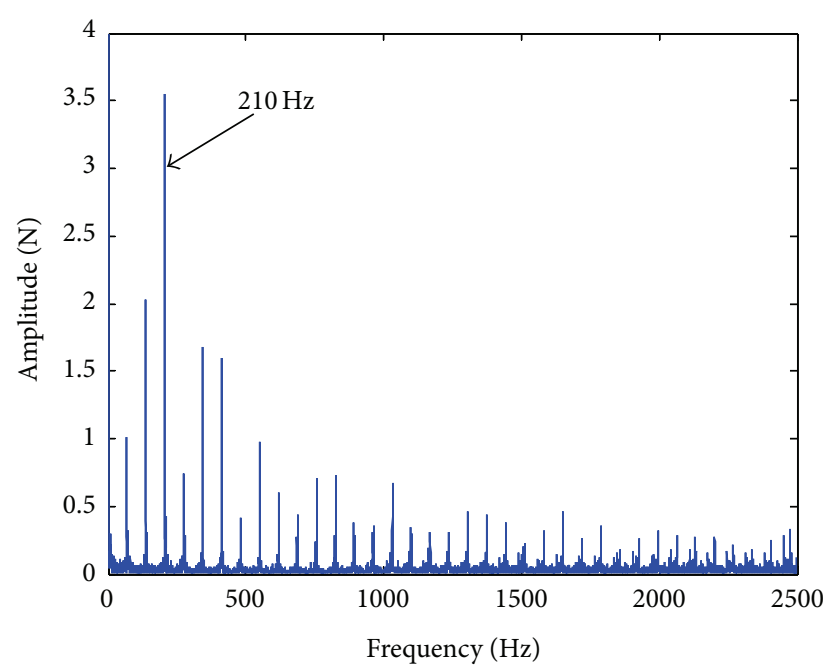

FIGURE 13: FFT-transform of force signal.

about $47 \%$ of the initial force in the first cycle which is most likely due to the deformation of grinding wheel. When a grinding wheel experiences deformations the actual depth of cut generated will be smaller, which subsequently causes a smaller grinding force value.

\section{Conclusions}

In this paper, a method of modeling and simulation for process-machine interaction in grinding of cemented carbide indexable inserts was presented.

A center coordinate adjusting method and a virtual grid method were adopted to model the topographies of grinding wheel. The methods proposed in this work take account of the random nature of abrasive grains and were able to avoid overlapping between abrasive grains in the binder in modeling. With the grinding wheel model at hand, a process model base on KSIM was able to generate forces as input data in process-machine interaction. A wheel-spindle structure
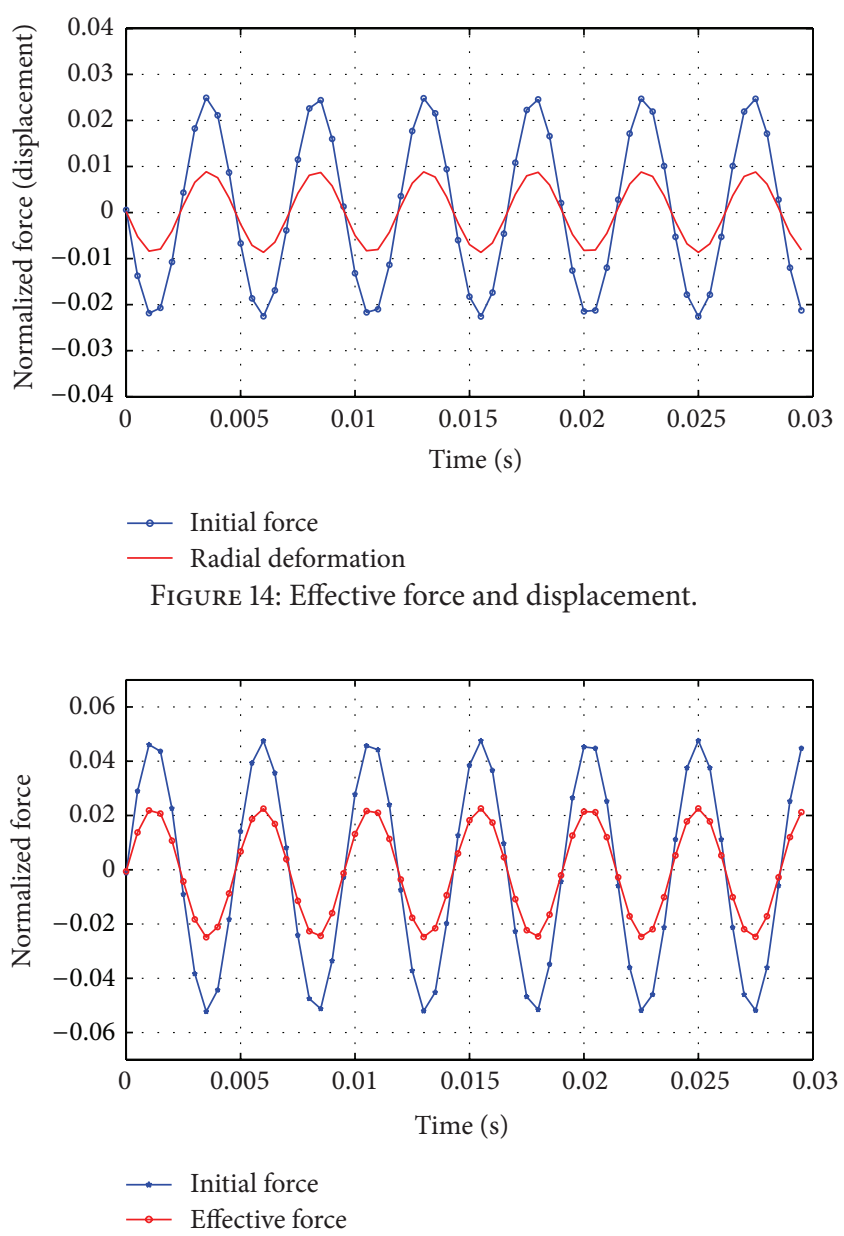

FIGURE 15: Initial force and effective force.

was selected and modeled by means of finite element method. The dynamic characteristic of the model was then verified by experimental modal analysis, which proves to match well with the experimental results.

The characteristic equation of the closed-loop dynamic grinding system was derived to account for the inner-relation of process and machine. A coupling simulation with an iteration algorithm was proposed to investigate the process and machine interaction. In the coupling approach, process and machine structure were dealt with in an integrated manner and interacted in synchronized cycles. Dynamic interaction of grinding forces and grinding wheel deformations were then investigated based on the proposed simulation method. It shows that the grinding wheel deformations have an influence on the cutting forces. The coupling method serves as a useful tool to understand well the interaction phenomenon in grinding of cemented carbide indexable inserts.

\section{Conflict of Interests}

The authors declare that there is no conflict of interests regarding the publication of this paper. 


\section{Acknowledgment}

This work was financially supported by the Science and Technology Innovation Project of Shannxi Province under Grant no. 2014KTDZ01-04, and the Science and Technology Major Special Project of China under Grant no. 2011ZX04003-021.

\section{References}

[1] Z. W. Zhong and V. C. Venkatesh, "Recent developments in grinding of advanced materials," The International Journal of Advanced Manufacturing Technology, vol. 41, no. 5-6, pp. 468480, 2009.

[2] E. Brinksmeier, Y. Mutlugünes, F. Klocke, J. C. Aurich, P. Shore, and H. Ohmori, "Ultra-precision grinding," CIRP AnnalsManufacturing Technology, vol. 59, no. 2, pp. 652-671, 2010.

[3] C. Brecher, M. Esser, and S. Witt, "Interaction of manufacturing process and machine tool," CIRP Annals-Manufacturing Technology, vol. 58, no. 2, pp. 588-607, 2009.

[4] J. C. Aurich, D. Biermann, H. Blum et al., "Modelling and simulation of process: machine interaction in grinding," Production Engineering, vol. 3, no. 1, pp. 111-120, 2009.

[5] Y. Lei, J. Lin, D. Han, and Z. He, "An enhanced stochastic resonance method for weak feature extraction from vibration signals in bearing fault detection," Proceedings of the Institution of Mechanical Engineers, Part C: Journal of Mechanical Engineering Science, vol. 228, no. 5, pp. 815-827, 2014.

[6] J. W. Xiang, T. Matsumoto, Y. X. Wang, and Z. Jiang, "A hybrid of interval wavelets and wavelet finite element model for damage detection in structures," Computer Modeling in Engineering \& Sciences, vol. 81, no. 3-4, pp. 269-294, 2011.

[7] J. Xiang, T. Matsumoto, J. Long, Y. Wang, and Z. Jiang, "A simple method to detect cracks in beam-like structures," Smart Structures and Systems, vol. 9, no. 4, pp. 335-353, 2012.

[8] H. K. Tönshoff, J. Peters, I. Inasaki, and T. Paul, "Modelling and Simulation of Grinding Processes," CIRP Annals-Manufacturing Technology, vol. 41, no. 2, pp. 677-688, 1992.

[9] E. Brinksmeier, J. C. Aurich, E. Govekar et al., "Advances in modeling and simulation of grinding processes," CIRP AnnalsManufacturing Technology, vol. 55, no. 2, pp. 667-696, 2006.

[10] Y. Altintas, C. Brecher, M. Weck et al., "Virtual machine tool," CIRP Annals-Manufacturing Technology, vol. 54, no. 2, pp. 115138, 2005.

[11] D. A. Doman, A. Warkentin, and R. Bauer, "Finite element modeling approaches in grinding," International Journal of Machine Tools and Manufacture, vol. 49, no. 2, pp. 109-116, 2009.

[12] T. A. Nguyen and D. L. Butler, "Simulation of surface grinding process. Part 2. Interaction of the abrasive grain with the workpiece," International Journal of Machine Tools and Manufacture, vol. 45, no. 11, pp. 1329-1336, 2005.

[13] Z. B. Hou and R. Komanduri, "On the mechanics of the grinding process-part I. Stochastic nature of the grinding process," International Journal of Machine Tools and Manufacture, vol. 43, no. 15, pp. 1579-1593, 2003.

[14] C. Brecher and S. Witt, "Simulation of machine process interaction with flexible multi-body simulation," in Proceedings of the 9th CIRP International Workshop on Modeling of Machining Operations, pp. 171-178, Bled, Slovenia, 2006.

[15] P. Herzenstiel, R. C. Y. Ching, S. Ricker, A. Menzel, P. Steinmann, and J. C. Aurich, "Interaction of process and machine during high-performance grinding: towards a comprehensive simulation concept," International Journal of Manufacturing Technology and Management, vol. 12, no. 1-3, pp. 155-170, 2007.

[16] K. Weinert, H. Blum, T. Jansen, and A. Rademacher, "Simulation based optimization of the NC-shape grinding process with toroid grinding wheels," Production Engineering, vol. 1, no. 3, pp. 245-252, 2007.

[17] J. C. Aurich and B. Kirsch, "Kinematic simulation of highperformance grinding for analysis of chip parameters of single grains," CIRP Journal of Manufacturing Science and Technology, vol. 5, no. 3, pp. 164-174, 2012.

[18] G. Warnecke and U. Zitt, "Kinematic simulation for analyzing and predicting high-performance grinding processes," CIRP Annals-Manufacturing Technology, vol. 47, no. 1, pp. 265-270, 1998.

[19] X. L. Zhang, B. Yao, and W. Feng, "Modeling of virtual grinding wheel based on random distribution of multi abrasive grains and prediction of grinding force," Acta Aeronautica et Astronautica Sinica, 2014.

[20] J. C. Aurich, A. Bouabid, P. Steinmann et al., "High-performance surface grinding," in Process Machine Interactions, pp. 81100, Springer, Berlin, Germany, 2013. 

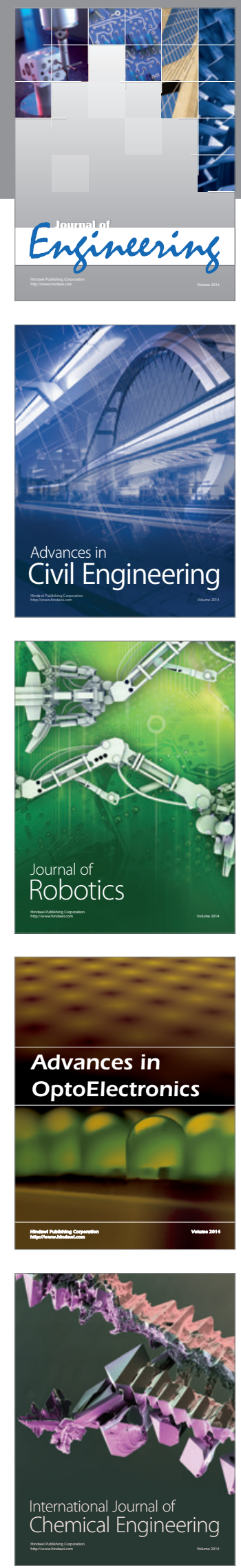

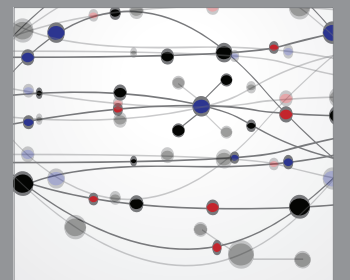

The Scientific World Journal
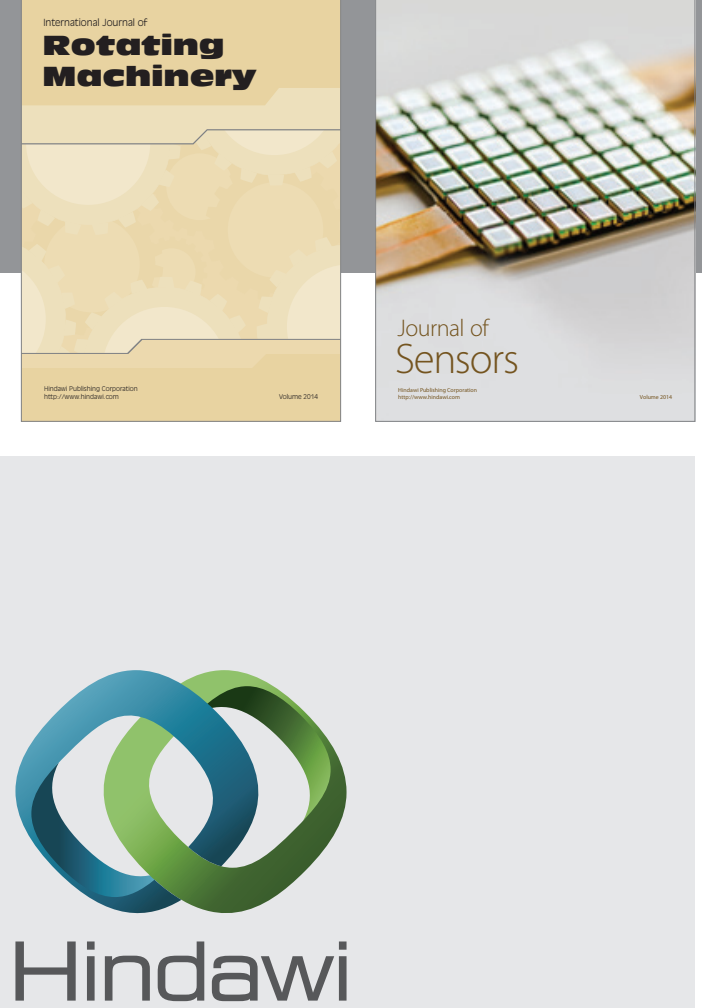

Submit your manuscripts at http://www.hindawi.com
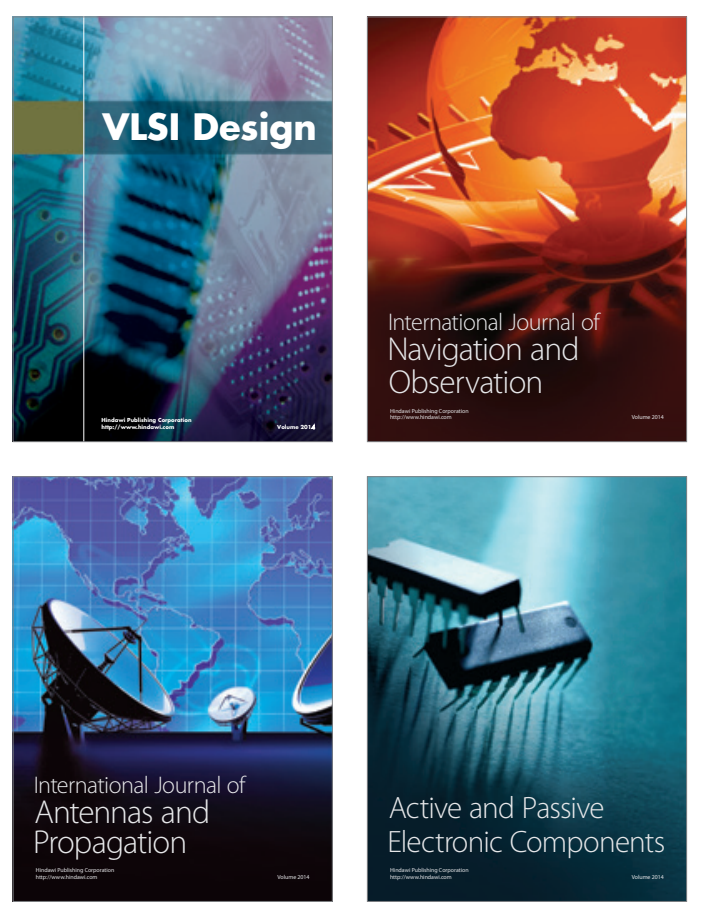
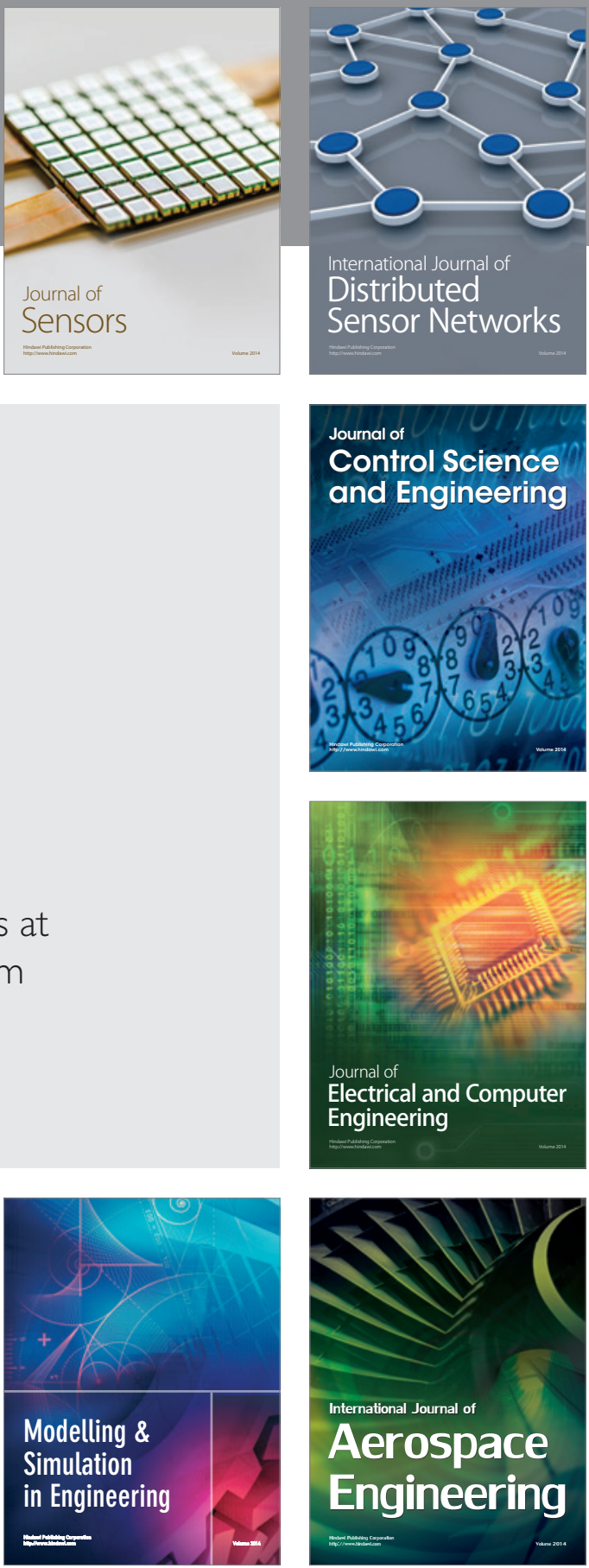

Journal of

Control Science

and Engineering
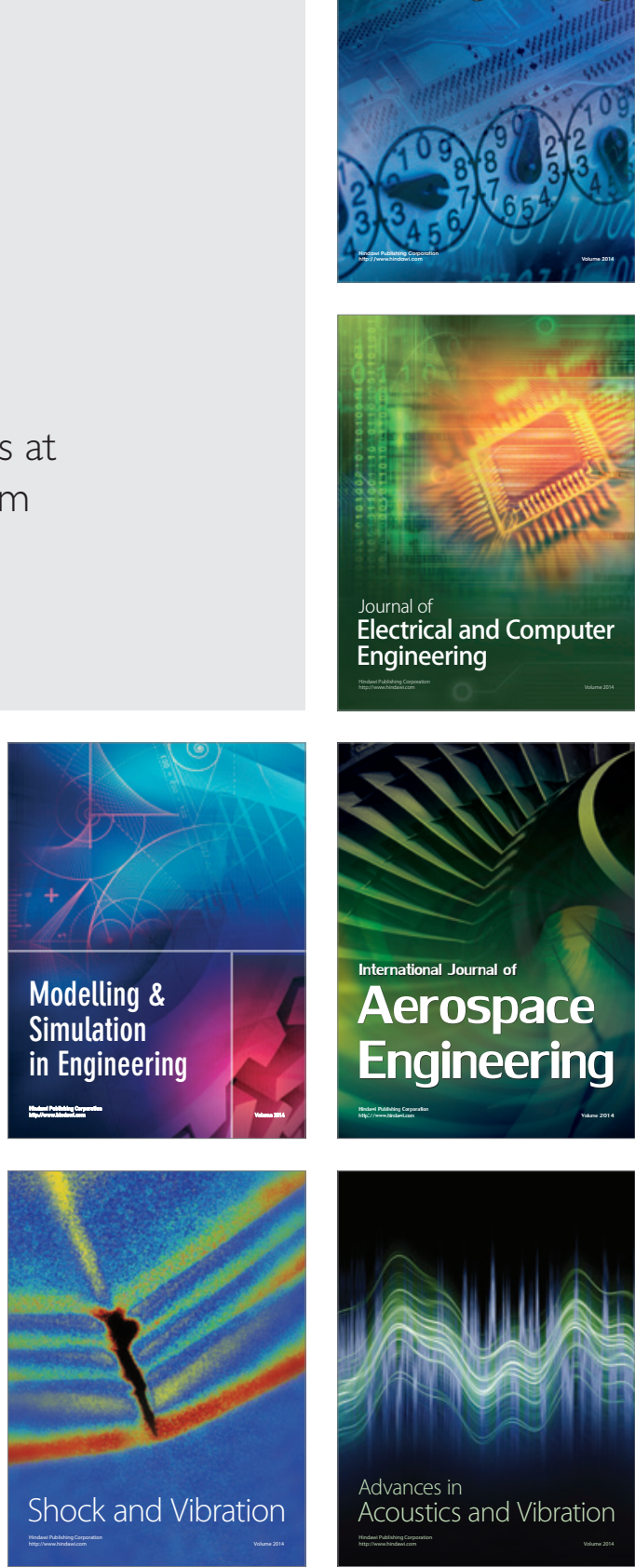